\title{
Supply chain cost research: a bibliometric mapping perspective
}

\author{
Edgar Ramos \\ Universidad Peruana de Ciencias Aplicadas, Lima, Peru \\ Steven Dien \\ University of Southern California, Los Angeles, California, USA \\ Abel Gonzales \\ Universidad Peruana de Ciencias Aplicadas, Lima, Peru \\ Melissa Chavez \\ Universidad Nacional de Ingenieria, Lima, Peru, and \\ Ben Hazen \\ Logistikum, University of Applied Sciences Upper Austria-Campus Steyr, \\ Steyr, Austria
}

\begin{abstract}
Purpose - The purpose of this paper is to review the literature on logistics and supply chain costs to provide an analysis of sources of publication, citations and authorship using bibliometric analysis techniques (VOSviewer and CitNetExplorer tools).

Design/methodology/approach - A review of 756 articles published during the period 2014 to 2019 referenced in the Scopus database was performed. The review was limited to articles published in English and directly related to logistics and supply chain costs.

Findings - The research identified more than 2,000 authors representing more than 5,000 keywords and 10,000 references from a total of 155 journals investigated. A critical synthesis of the resulting data revealed several insights about various aspects of studies in this field. For instance, the review identified a scarcity of academic publications in three key areas, namely "supply chain," "optimization" and "transportation", which are concepts focused on the total supply chain.

Originality/value - This research highlights important areas of attention for both researchers and practitioners considering costs associated with logistics and supply chain operations and strategies. The results can also help identify thematic areas, journals and topics for future research. The paper identifies and proposes research areas to contribute to the literature when challenges to investigating logistics and supply chain costs are discussed.
\end{abstract}

Keywords Logistics, Supply chain, Cost, Bibliometric analysis, VOSviewer, CitNetExplorer

Paper type General review

\section{Introduction}

Supply chain management (SCM) is considered as the coordination of material, information and financial flows within internal and external aspects of a firm's operations, in the different processes involved in adding value to the end customer (Pettersson and Segerstedt, 2013; Prajogo et al., 2016). Most organisations want their supply chain to be profitable, i.e. they want profits or costs to go hand in hand with the uncertainty of demand (Mangal and Gupta, 2015).

(C) Edgar Ramos, Steven Dien, Abel Gonzales, Melissa Chavez and Ben Hazen. Published by Emerald Publishing Limited. This article is published under the Creative Commons Attribution (CC BY 4.0) licence. Anyone may reproduce, distribute, translate and create derivative works of this article (for both commercial and non-commercial purposes), subject to full attribution to the original publication and authors. The full terms of this licence may be seen at http://creativecommons.org/licences/by/4.0/ legalcode

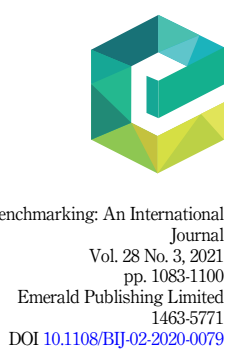


BIJ

28,3

1084

Also, managing the total cost of sourcing, manufacturing, delivery and logistics of products is a key element in providing a competitive advantage (Whicker et al., 2009). A simulation study revealed valuable managerial insights regarding how demand and cost uncertainty affects the profits, the risks as well as the global outsourcing and quick-production decisions of supply chain firms under competition (Liu and Nagurney, 2013). Also, companies are considering aspects such as economic management to integrate sustainability into their SCM. Even though a chain can only be formed when a win-win situation and profitability maximisation for all members is established, is difficult since some benefits of joining the chain are difficult to quantify in monetary terms (Chiadamrong and Wajcharapornjinda, 2012). Usually, the risks with a low probability of occurrence are the ones that lead to high costs (Alsobhi et al., 2018). It is crucial to know the risks presented in SCM, and these risks can be defined as any factors that result in interruptions in the flow of materials, information and funds in a supply chain that result in undesirable consequences and vulnerability (Vishnu et al., 2019). Weskamp et al. (2018) highlighted various risks, including the risk of increasing the costs involved, since many companies aiming to propose strategies that increase the chances of success also significantly increase their costs. There are four common cost categories applied to logistics cost structure such as transportation, cargo handling, warehousing, inventory and logistics administration that must be taken into account for calculation (Rybakov, 2017).

Several authors have investigated cost-related issues in the supply chain. For instance, Seuring and Muller (2008) stated that possible cost reductions had increased attention on implementation, legislative and environmental problems. Chen and Notteboom (2014) discussed the importance of value-added logistics services in cost terms to the supply chain. Hafezalkotob and Khalili-Damghani (2015) sought to minimise logistic costs and maximise service level in a three-echelon multi-product supply chain. Lihua Chen et al. (2018) developed a cost-based decision model is presented for determining integrated decisions involving capacity management and delivery performance. $\mathrm{Hu}$ et al. (2019) determined who should invest in reducing cost in a supply chain consisting of one manufacturer and one retailer. Hames et al. (2019) analysed reverse logistics by calculating the costs of all specific activities in advance. Also, in recent years academics have addressed specific issues such as risk management (Vishnu et al., 2019), resiliency (Datta, 2016) and supplier management (Xiao et al., 2020). The studies mentioned above provide relevant information on costs through structured theories and their classification for future research topics.

In recent years additional analyses have been used to help identify the various emerging areas of research, bibliometric and network analyses are examples of it (Ferreira et al., 2014). The bibliometrics analysis is a meta-analytical research tool (Saha et al., 2020). Bibliometric analysis related to supply chain costs will provide an overview in this area from the field of library and information science (Merigó and Yang, 2017). It often utilises information system tools to conduct a comprehensive search of relevant articles that appear in multiple databases and quantitative methods (Wang et al., 2017). Besides, it is considered that citations and cocitation analysis can provide objectively quantitative data and can be presented visually (Shiau and Dwivedi, 2013).

The analyses in this paper are essential to provide the reader (either academic or professional) with a summary of the current state of the field related to authors, countries, topics and areas; possible emerging themes; and encourage researchers to collaborate and further expand knowledge of the domain (Ozkose and Gencer, 2017). To address SCM, this research:

(1) reviews the literature on logistics costs and SCM; 
(2) provides a complete overview of the field through the use of bibliometric and network analysis techniques; through the evaluation of 286 articles published in the last five years through the identification of main authors, countries and key research topics;

(3) retrieves and compares the most influential works based on quotes and page ranks.

In this investigation, bibliometric information system tools were used to review the publications in logistics and SCM thoroughly. The results of this study provide additional information on the most influential journals, authors, interrelations, keywords and thematic trends according to the information found in papers in this field (Ferreira et al., 2014; Merigó and Yang, 2017; Ozkose and Gencer, 2017). In addition, it provides established and emerging research areas that encourage academics to complement and expand research on total cost, logistics costs and SCM (Whicker et al., 2009).

The first section reviews the literature on logistics costs in SCM. Then the second section presents the research methodology. The third section presents an exhaustive analysis using rigorous bibliometric tools, which is followed by a discussion of the results. The final section presents the conclusions, limitations and future research directions.

\section{Literature review on logistics costs and SCM}

This section analyses logistics costs and their relation to SCM followed by details of the tools utilised for the analysis.

\subsection{Approaches to logistics costs}

Voordijk (2010) referred to the logistics costs of a supply chain as those involved in the management and storage of inventories, transportation and those incurred for physical distribution. Logistics costs are the result of the process that begins with the supply of the raw material and ends with the delivery of the product(s) to the customer, and this involves the main logistics operations such as supply, physical conversion and distribution (Rybakov, 2017). Silva et al. (2014) also included an after-sales service into logistics costs. However, Havenga (2010) stated that logistics costs comprise only the cost of transportation, storage management and administration. Weiyi and Luming (2009) posited that logistics costs explicitly cover acquisition, transportation, delivery, purchase, volume and packaging costs while implicit costs cover maintenance of the inventories, opportunity, interests, service goods and the additional cost of the logistics services for an erroneous logistics operation. Jena and Seth (2016) separated cost into controllable (performance efficiency, planning transportation, the effectiveness of predicting the demand, information exchange within an organisation) and non-controllable factors (macroeconomic factors such as oil prices).

Table 1 showcases the different appliances of logistics costs in the industry, including measuring and managing them.

It is important to understand that a process structure of a company defines the cost structure, too; this cost structure defines a set of cost elements of an optimisation model (Ilin and Anisiforov, 2014). While taking into consideration that better logistics service entails higher logistics costs, Jeffery et al. (2008) developed an approach for determining inventory levels that result in a minimum cost customer service level. Hafezalkotob and KhaliliDamghani (2015) conclude that the most significant indicators of logistics service are: order cycle time and order fill rate.

\subsection{Helpful tools for logistics costs management}

Specific tools have been developed to improve the visibility of logistics costs focused on three different aspects: cost, customer and product. To improve the accuracy of cost analysis in a 
BIJ
28,3

1086

Table 1.

Representative

logistics cost-related

articles

\begin{tabular}{|c|c|c|}
\hline Title & Application & Author \\
\hline $\begin{array}{l}\text { The performance of logistics service } \\
\text { providers and the logistics costs of } \\
\text { shippers: a comparative study of Finland } \\
\text { and Switzerland }\end{array}$ & $\begin{array}{l}\text { The study presented descriptive evidence } \\
\text { that the logistics costs of Finnish shippers are } \\
\text { systematically higher than the corresponding } \\
\text { costs of Swiss shippers }\end{array}$ & $\begin{array}{l}\text { Solakivi et al. } \\
\text { (2018) }\end{array}$ \\
\hline $\begin{array}{l}\text { Measuring the invisible: a key performance } \\
\text { indicator for managing construction } \\
\text { logistics performance }\end{array}$ & $\begin{array}{l}\text { The research proposed setting a key } \\
\text { performance indicator to manage logistics } \\
\text { costs in their case study }\end{array}$ & $\begin{array}{l}\text { Ying et al. } \\
\text { (2018) }\end{array}$ \\
\hline $\begin{array}{l}\text { Logistics cost management: insights on } \\
\text { tools and operations }\end{array}$ & $\begin{array}{l}\text { Reviews logistics cost literature with a focus } \\
\text { on identifying the possibilities tools that can } \\
\text { be used on logistics cost management }\end{array}$ & $\begin{array}{l}\text { Dos Santos } \\
\text { et al. (2016) }\end{array}$ \\
\hline $\begin{array}{l}\text { Integrated cost optimisation in a two-stage, } \\
\text { automotive supply chain }\end{array}$ & $\begin{array}{l}\text { Modelled the integrated production and } \\
\text { transportation planning problem while } \\
\text { taking into account realistic conditions and } \\
\text { multiple types of incurred costs }\end{array}$ & $\begin{array}{l}\text { Masoud and } \\
\text { Mason (2015) }\end{array}$ \\
\hline
\end{tabular}

supply chain, Chiadamrong and Wajcharapornjinda (2012) introduced a cost-reducing activity that they termed activity-based costing $(\mathrm{ABC})$. $\mathrm{ABC}$ seeks to improve the monitoring of costs for individual products or customers (Bastl et al., 2010; Christopher and Holweg, 2011; Silva et al., 2014). It consists of a two-step procedure; first resource costs are allocated to activities and then costs are allocated to cost objects by cost drivers (Hofmann and Bosshard, 2017). Selection of the activity cost drivers (namely, transaction, duration and intensity drivers) reflects a subjective trade-off between accuracy and the cost of measurement (Somapa et al., 2012). Besides, ABC can be used in the place of traditional methods, since it can provide better logistic management than the others (Pettersson and Segerstedt, 2013). The traditional accounting system is function-oriented and not process-oriented, with cost captured at a level of aggregation too high with more difficulties to identify the right cost (Hofmann and Bosshard, 2017).

\subsection{Logistics costs and SCM}

The key to success and to stay competitive in today's global marketplace is to reduce the total cost to its lowest level and to eliminate waste in all units of a company (Manzouri et al., 2014). Logistics are considered an essential channel of customer satisfaction, cost-effectiveness and optimum utilisation of resource in an organisation (Mangla et al., 2017). Also, it is beneficial for organisations to have a set of efficient tools to reduce costs and waste, to provide an effective service for customer demand and to understand their system behaviour (Carvalho et al., 2017; Singh and Pandey, 2019).

Since logistics costs must have a direct relationship with other cost categories, they must be managed following the precepts of integrated logistics, globally observing the economic performance of the organisation and complying with the level of service established for customers. Chiadamrong and Wajcharapornjinda (2012) classified costs and proposed a model to quantify them throughout the supply chain in which the coordination of the supply chain must be considered, trust must be built in the chain and order and production variability must be reduced to avoid forecasting errors. Table 2 presents illustrative papers that the impact of costs across the supply chain has been applied through many perspectives.

The great dilemma about the total logistic costs is visibility since the costs incurred in the logistic processes are incorporated in many financial statements, it faces difficulties in identifying costs is the way in which they are classified and enumerated in the balance by the companies (Silva et al., 2014). These difficulties would lead companies to not being able to 


Title
Costs and benefits of using cross-
docking in the retail supply chain A case
study of an FMCG company

Supply chain network design based on cost of quality and quality-level analysis

Integrated method of analysing logistics costs in supply chain

Development of a multi-period model to minimise logistic costs and maximise service level in a three-echelon multiproduct supply chain considering backorders
Application

The purpose of this paper is to investigate the costs/benefits of implementing the cross-docking strategy in a retail supply chain context using a cost model

The purpose of this paper is to explore the impact of the cost of quality (COQ) expenditure allocations on a capacitated supply chain (SC) network

Evaluated effectiveness using minimum total logistics costs and assessed the impact of different logistics operation factors

The mathematical model selected the optimum numbers, locations and capacity levels of plants and warehouse to deliver everything the supply chain needs with minimum logistics cost and high service level
Supply chain cost research

Benrqya (2019)

Alglawe et al. (2019)

1087

Lukinskiy et al. (2015)

Hafezalkotob and Khalili-Damghani (2015)

Table 2.

Representative cost and supply chainrelated articles

quantify the hidden benefits and savings of their supply chains (Chiadamrong and Wajcharapornjinda, 2012). It is essential to develop a system for logistics costs aligned with the demand and inventory management of the supply chain so that it would be helpful in the decision-making process (Mangal and Kumar Gupta, 2015). The processes of measurement, accumulation and appropriation of costs do not have to comply with legal precepts or generally accepted accounting principles (Ying et al., 2018). Notably, the measurement of logistics costs is essential in improving the management of supply chain costs.

\section{Research methodology}

One must understand the area of interest on which the study will focus to initiate the investigation. Also, researchers must stay informed through a periodic review of the changes in the research topic, since these vary with the discovery of new technologies and trends for the different branches of the industry. Although it is a time-consuming task, it ensures that the researcher does not miss any new development, while also helping to identify weaknesses and future opportunities in the field of supply chain costs (González-Benito et al., 2013).

Structured reviews of the literature should be carried out ideally through a process of defining appropriate keywords, searching for relevant texts and completing the analysis. Figure 1 provides a general description of the literature review describing its steps, objectives, adopted methods, tools and software used.

As part of the methodological review, it was considered convenient to use the Scopus database as it offers a global vision of research knowledge with intelligent tools to segment, evaluate and select articles according to search criteria relevant to the topic. Besides, it has a complete database that covers various publishers such as Elsevier, Springer, InderScience, Taylor \& Francis, Emerald and IEEE, among others.

The period considered was from 2014 to 2019, and it was ensured that the title and summary contained the main keywords "logistics costs" and "supply chain". Besides, using Boolean operators, secondary keywords such as "optimization" and "transportation" were included. The authors excluded any article written with similar ideas, but that did not directly address the perspective of logistics costs or supply chain costs, such as "biofuels", 
$\mathrm{BIJ}$

28,3

1088

Figure 1.

Steps, objectives, methods, tools and programs/software

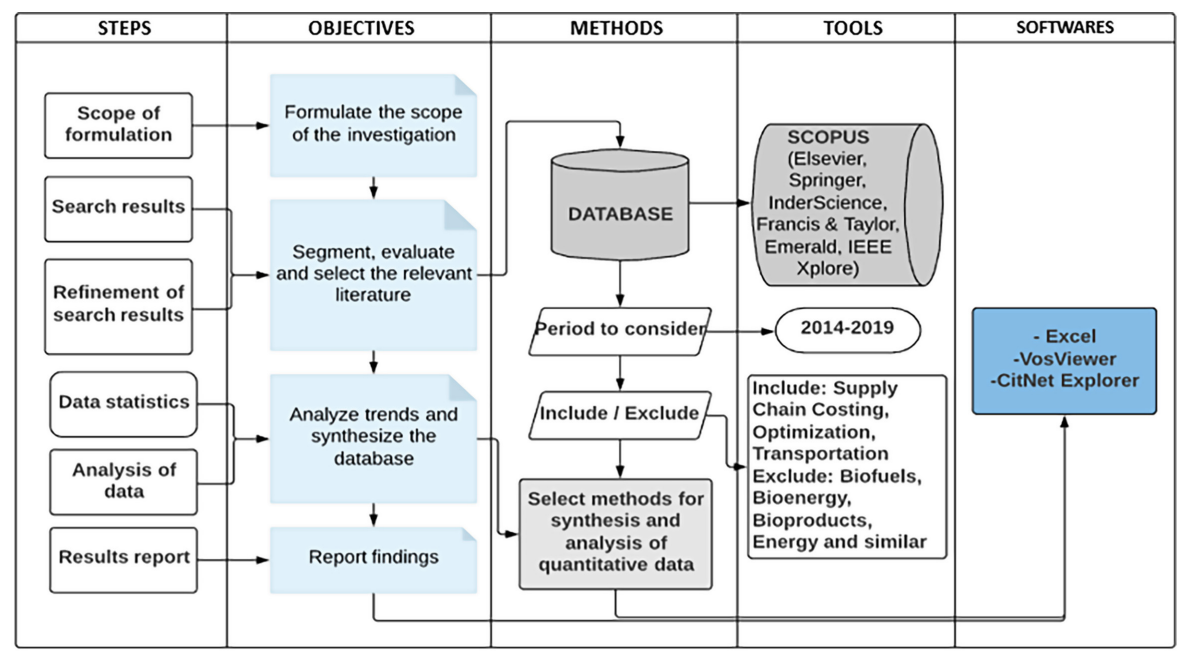

"bioenergy", "bioproducts", etc. The results of the initial search for articles about logistics costs in the supply chain for the period 2014-2019 yielded 1,815 articles, of which 202 articles $(11.2 \%)$ were related to "optimization" and $162(8.93 \%)$ were related to "transportation" (see Table 1).

Relationships between the main and secondary keywords, the only articles that were taken into consideration were the ones in their final version published in academic journals and written in the English language (see Table 2).

A detailed inspection of the 1,815 articles yielded by the initial search (see Table 1) articles revealed the duplication of some articles in the counts. Duplication happened due to common keywords between two or more search iterations such as "optimization" with "logistics costs and supply chain" and "transportation" with "logistics costs and supply chain", among others. Also, it was noted that the number of publications reflected against the main author was also replicated in the co-authors' publication count.

Therefore, the results of the search were further refined to extract unique articles and thus avoid redundancies or duplications. Also, more limitations were established in the search queries to limit results to articles with the exact keywords and to incorporate the considerations mentioned above for Table 2 . The results of this refined search are shown in Table 3.

\subsection{Analysis of statistical data}

Once the database was segmented (see Table 3), a statistical analysis of the 756 articles obtained was carried out to identify trends, journals, authors and the years in which they were published (2014-2019). Figure 2 shows the distribution of articles by the year and by journal throughout the study period. The publication year analysis of all the articles shows that the Journal of Cleaner Production had the largest number of articles (33), representing 4\% of the total. However, other journals were also influential on a minor degree, including the International Journal of Production Economics (29), Computers and Industrial Engineering (25), the International Journal of Production Research (24) and the European Journal of Operational Research (20). 


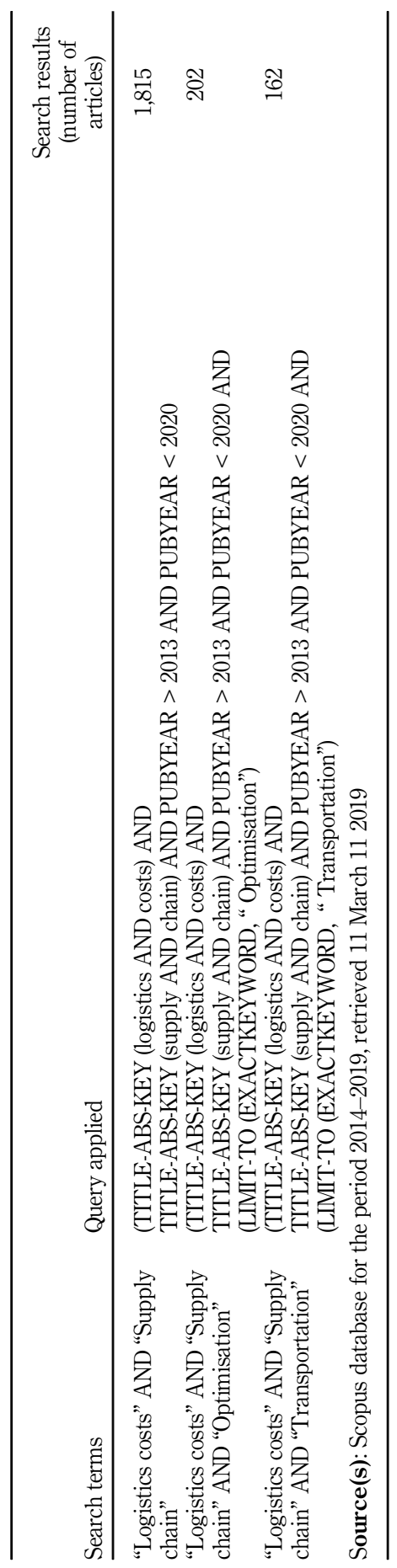

Supply chain cost research

1089

Table 3.

Publications in logistics costs on optimisation and transportation in the supply chain 
BIJ

28,3

1090

Figure 2.

Articles per year by journal

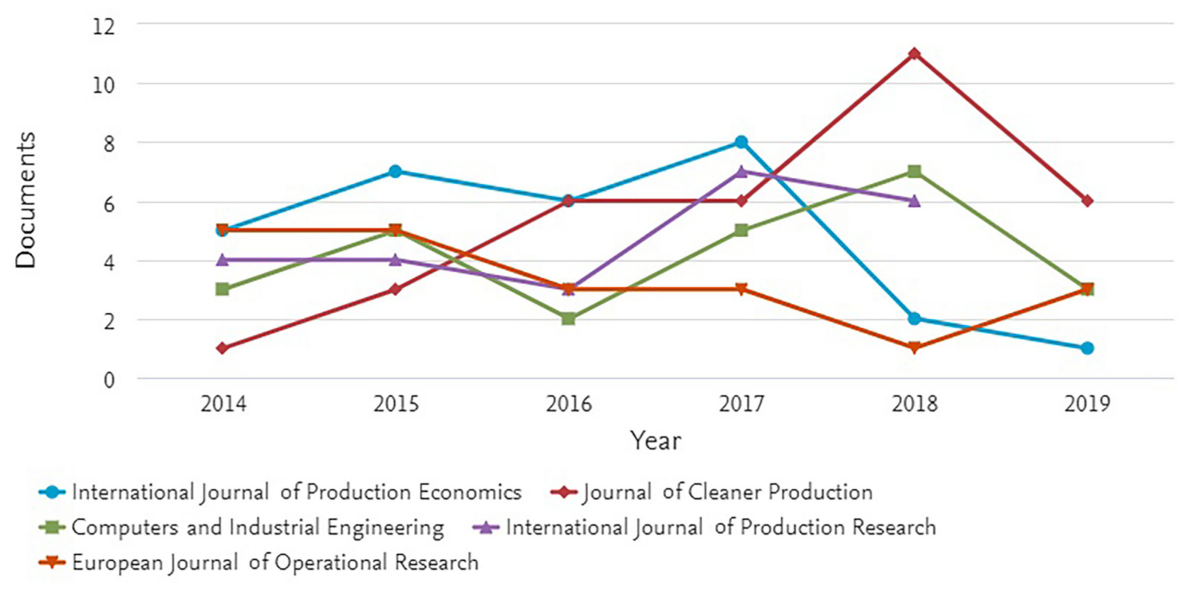

An analysis of each author contribution concerning the articles they were involved with is provided in Figure 3 since it is valuable to evaluate their importance. W. Liu had the most articles published on the subject (eight), followed by M. Jaber, D. Connor and V. Lukinskiy (six each). It should be noted that, for this analysis, the minimum number of articles per author considered was three.

\subsection{Bibliometric analysis}

This study used the software tools VOSviewer (Van Eck and Waltman, 2010) and CitNetExplorer (Van Eck and Waltman, 2017) for the bibliometric analysis (citation and cocitation analysis). Both tools are packages of analysis and visualisation software that help to reveal important finding on a topic and its evolution.

The authors collected and analysed data from the main collection of Scopus and collected all articles from academic journals that were published between 2014 and 2019 and that contained the search terms "logistics costs", "supply chain", "optimisation", "transportation" and "bibliometric analysis" in any of the keyword, title or summary fields. As stated, the sample was limited to articles published in English, in the final form, in academic journals. The search yielded 756 articles, representing more than 2,000 authors, more than 5,000

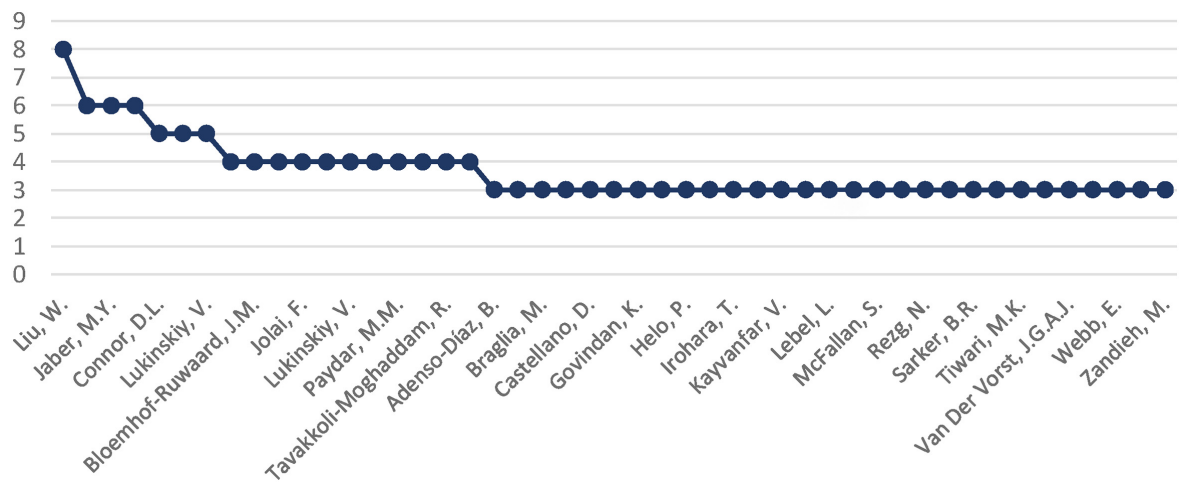

Figure 3.

Distribution of the papers per author 
keywords and more than 10,000 references. Figure 4 shows the relationship between the "keywords" based on the number of references they share. In contrast, Figure 5 shows the relationship between journals (but as a density display rather than a network).

Figure 6 presents a timeline of the publication citations network from 2014 to 2019, where each circle represents a publication and each colour a group of publications. It also shows the relationship between publications that cover the same topic. Although Figure 4 uses the same database, Figure 6 shows how authors' different publications have been cited over time.
Supply chain cost research

\section{Results and discussion}

Thanks to the analysis carried out using the VOSviewer and CitNetExplorer bibliometric tools, it was possible to obtain keywords that were considered relevant to finding the most pertinent information for the present investigation. In the case of keywords, the type of analysis was co-occurrence, where the unit of analysis was "all keywords" and the quantitative method was "full counting". Table 4 shows the main 11 keywords (out of a total of 148) and their occurrences.

It was also possible to obtain the leading journals where the most significant number of publications relevant to the present research is concentrated. Here, the type of analysis used was co-citation, where the unit of analysis was "cited sources" and the quantitative method was "full counting". The leading 15 journals (out of a total of 155) and their respective citations are shown in Table 5.

Concerning the authors who had greater participation in the research regarding the number of co-citations, the type of analysis performed was "co-authorship", where the unit of analysis was "authors" and the quantitative method was "full counting." Table 6 shows the relevance of the ten authors with the highest number of citations that have contributed to the research (see Tables 7 and 8 for additional details).

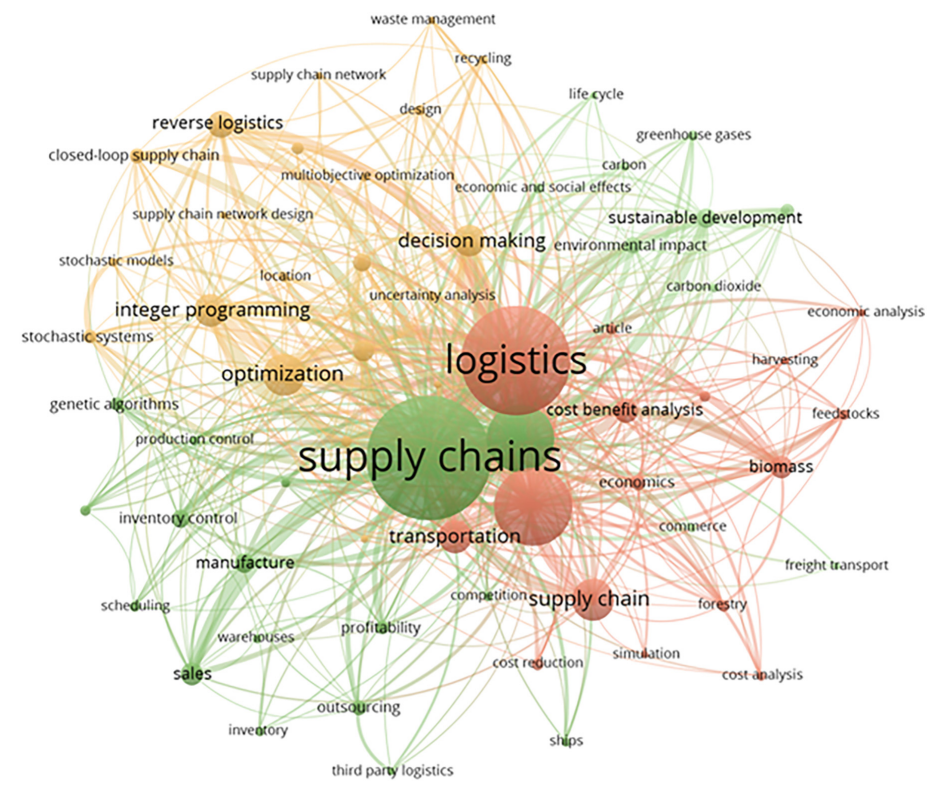

Figure 4.

Keyword matching (elaborated with VOSviewer) 
BIJ

28,3

\section{2}

Figure 5.

Density visualisation of journals (elaborated with VOSviewer)

Figure 6.

Citation network of publications (elaborated with CitNetExplorer)

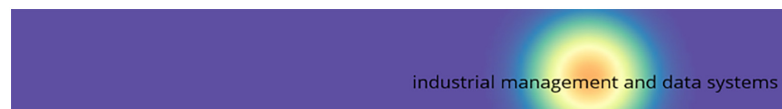

international journal of logistics management

expert systems with applications

applied mathematical modelling

international journal of production economics

international journal of production research

computers and electronics in agriculture

\section{\& EOSviewer}

\section{journal of cleaner production}

transportation research part e: logistics and transportation sustainability (Switzerland)
2014

2016

2017

2018

2019

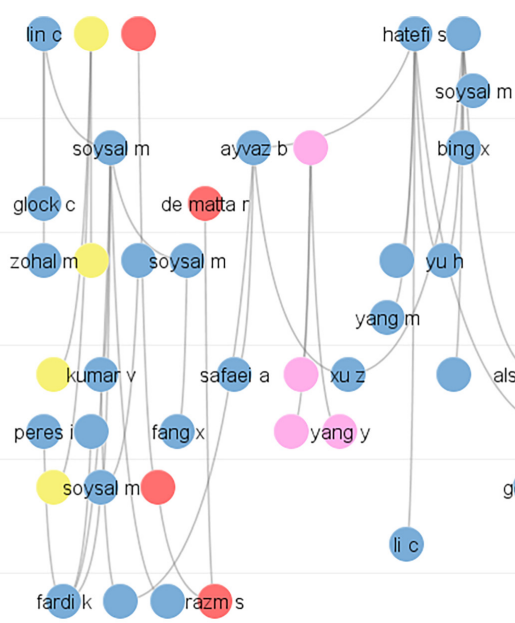

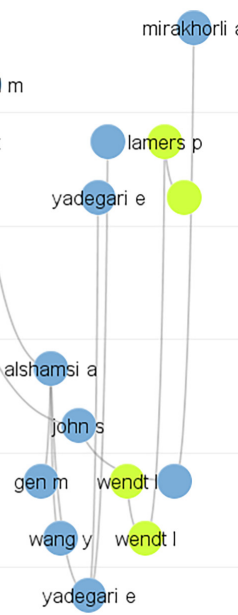

yadegari e

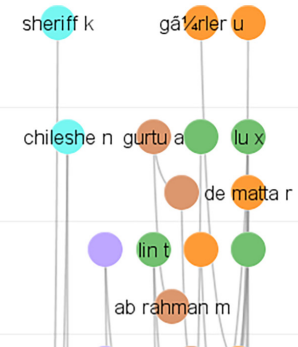

golshahi-roudbaneh a yu y

javadian n perrin a

safaei a darvish m

cheraghalipour a

albashahchohn گ CitNetExplorer
Table 4.

General results: bibliographic data on supply chain research, optimisation and transportation

\begin{tabular}{lcccr}
\hline Bibliometric data & Supply chain & Optimisation & Transportation & Total \\
\hline Final publications & 1,772 & 199 & 161 & 360 \\
Articles & 1,121 & 132 & 102 & 234 \\
Journals & 1,205 & 143 & 109 & 252 \\
Language - English & 1,760 & 197 & 353 \\
Source(s): Scopus database for the period 2014-2019, retrieved 11 March 2019 & &
\end{tabular}




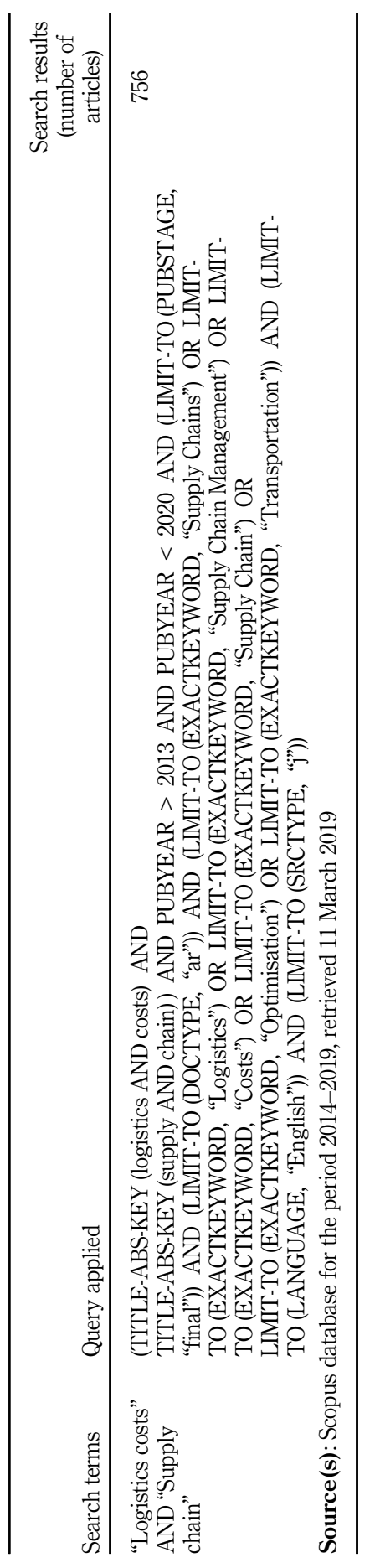

Supply chain cost research

1093

Table 5. Application of the refined query 
BIJ

1094

\subsection{Implications for research}

The findings showcase the different dimensions related to supply chain cost, revealing new field studies in the subject and their connection to logistics and supply chain cost. The bibliometric analysis presents the principal authors, context and journals that are critical to the state-of-art understanding around the discussed topic.

This bibliometric paper enables researches to identify research areas to be recognized within the one structure and connections regarding the cost in the supply chain, transportation and optimization, for example. In terms of research, this structure, before mentioned in the bibliometric analysis, determines the scope of the study and identify some gaps in cost supply chain studies.

This investigation could be used in future research to understand the key supply chain cost metrics and other operational supply chain management themes and identify potential operational processes where the total cost supply chain needs to be measured from a supply chain perspective or across different disciplines.

\subsection{Implications for practice}

The present study indicates that organizations face the challenge of quantifying supply chain cost-benefit and improving the visibility of logistics cost. The results of the bibliometric analysis indicate that supply chain cost is primarily related to "optimization" and

\begin{tabular}{lcc}
\hline Keyword & Total occurrences & Percentage \\
\hline Supply chains & 416 & 22 \\
Logistics & 363 & 19 \\
Supply chain management & 248 & 13 \\
Costs & 214 & 11 \\
Optimization & 127 & 7 \\
Supply chain & 126 & 7 \\
Transportation & 96 & 5 \\
Integer programming & 95 & 5 \\
Decision making & 92 & 5 \\
Reverse logistics & 76 & 4 \\
Cost-benefit analysis & 68 & 4
\end{tabular}

Table 6.

Relationship between keywords, frequency of occurrence and the number of papers

\begin{tabular}{llccc}
\hline Rank & Source & $\begin{array}{c}\text { Scimago journal } \\
\text { rank }\end{array}$ & Quartile & $\begin{array}{c}\text { Total } \\
\text { citations }\end{array}$ \\
\hline 1 & European Journal of Operational Research & 2.21 & 1 & 1438 \\
2 & International Journal of Production Economics & 2.48 & 1 & 1216 \\
3 & International Journal of Production Research & 1.59 & 1 & 426 \\
4 & Omega & 3.29 & 1 & 317 \\
5 & Management Science & 6.08 & 1 & 268 \\
6 & Computers and Industrial Engineering & 1.33 & 1 & 239 \\
7 & Journal of Cleaner Production & 1.62 & 1 & 227 \\
8 & Journal of Business Logistics & 2.49 & 1 & 206 \\
9 & International Journal of Physical Distribution and & 2.41 & 1 & 199 \\
& Logistics Management & 1.19 & 1 & 192 \\
10 & Expert Systems with Applications & 2.10 & 1 & 186 \\
11 & Supply Chain Management: An International Journal & 1.86 & 1 & 184 \\
12 & Computers and Operations Research & & &
\end{tabular}

Table 7.

Relationship of journals and their co-citations
11 Supply Chain Management: An International Journal $12 \quad$ Computers and Operations Research 


\begin{tabular}{|c|c|c|c|c|c|c|}
\hline$\underline{\text { Rank }}$ & Author & $\begin{array}{c}\text { Total } \\
\text { articles }\end{array}$ & $\begin{array}{c}\text { Total } \\
\text { citations }\end{array}$ & Country & Institution & $0 \mathrm{St}$ \\
\hline 1 & W. Liu & 10 & 78 & China & College of Management and Economics & \\
\hline 2 & M.Y. Jaber & 6 & 99 & Canada & Ryerson University & \\
\hline 3 & M.K. Tiwari & 6 & 97 & India & Indian Institute of Technology Kharagpur & \\
\hline 4 & Y. Yang & 6 & 61 & France & Centre de Gestion Scientifique & 109 \\
\hline 5 & S.T. Brown & 6 & 57 & USA & McGill University & \\
\hline 6 & B.V. Lee & 6 & 57 & USA & $\begin{array}{l}\text { Johns Hopkins Bloomberg School of Public } \\
\text { Health }\end{array}$ & $\begin{array}{l}\text { Table } 8 . \\
\text { Top ten authors: the }\end{array}$ \\
\hline 7 & D.L. Connor & 5 & 57 & USA & HERMES Logistics Modelling Team & relationship betwee \\
\hline 8 & B. Karimi & 5 & 56 & Iran & Amirkabir University of Technology & author, number \\
\hline 9 & S. Pan & 5 & 51 & France & Centre de Gestion Scientifique & articles, co-citatic \\
\hline 10 & Y.Shi & 5 & 49 & China & Southwest Jiaotong University & country and institution \\
\hline
\end{tabular}

"transportation." Hence, management strategies have to focus on identifying supply chain cost-efficiency across those fields.

This investigation reveals the cost supply chain areas, topics and the connections that are critical for managing in the supply chain and shows the relations and potential consequences for the managers. That is, this study supports managers' assessment of costs by mentioning the $\mathrm{ABC}$ costing to improve and monitor the costs for individual products or customers. Besides, it offers the empirical foundation through previous studies on logistics cost and supply chain.

Finally, the study attempts to show the structure and understanding of the concept of supply chain costs, which can help guide practitioners to develop and implement supply chain strategies to reduce total costs and minimize waste in the supply chain. Consequently, the understanding of key factors for managing the supply chain costs regarding optimization and transportation areas of their businesses will help when making critical cost-benefit decisions to gain positive results at the company and supply chain level.

\subsection{Limitations}

There are some study limitations important to mention. One of the primary limitations is related to the selected database. Since only Scopus was used, other published materials available elsewhere might have been missed. Different types of publications, such as proceedings papers, books and theses were not investigated to contribute to this bibliometric study. Also, the clustering that resulted from the co-citation analysis will only bring out the most common elements and enhance some ideas and concepts, other useful or essential publications may have been ignored. There is additional knowledge that could be gained from other dimensions of analysis, such as co-occurrence analysis or bibliographic coupling; however, these analyses were not central to this study, and thus reporting these results would be of limited value.

\section{Conclusions}

A wide range of crucial data has been detailed and utilised, based on the analysis of publications and citations, using statistical analysis and bibliometric mapping. The current state of research has been evaluated by examining the methods, areas, level of research and the design of the same with contributions, main theories and tools/software (Zhang et al., 2013). Also, a critical synthesis of the resulting data has revealed impressive knowledge about various aspects of the study, as explained below. 
BIJ

28,3

1096

5.1 Research knowledge on "optimisation" and "transportation" in the supply chain

The initial statistical data on the search results related to logistics costs, after refinement and the use of Boolean operators, yielded 756 complete articles related to optimisation and transportation in the supply chain (see Table 3). Besides, the research clearly shows that the concepts of optimisation (202 articles) and transport (162 articles) are very influential since together they add up to 364 articles, which represents almost half of the database (48.14\%).

\subsection{Publications in journals and citations}

The analysis of the main articles in logistics costs in the supply chain research indicates that the more significant number of citations were published in five esteemed journals, the Journal of Cleaner Production and the International Journal of Production Economics, followed by Computers and Industrial Engineering, the International Journal of Production Research and the European Journal of Operational Research. It should be noted that these journals accounted for 131 articles, which represents $17.32 \%$ of the total.

\subsection{Analysis of the influence of authors and citations}

It was observed from the bibliometric analysis that authors such as Weihua Liu (eight papers) from the University of Taijin, China and Shawn Brown (six papers) from the Technological University of Montreal, Canada, have contributed the most articles on logistics costs in the supply chain.

In the case of optimisation studies, authors such as Nidhal Rezg (four papers) from the University of Lorraine, and Eric Ballot (three papers) from the Scientific Management Centre, both in France, had most articles with a high number of citations. In the case of transport studies based on the logistics costs approach, Mohamad Jaber from the University of Ryerson in Toronto, Canada, had the most papers (five) related to the subject. In contrast, Cathy Macharis from Brussels University, Belgium, had four. Reputable database repositories such as Scopus provide enough resources of quality publications in various thematic areas to provide researchers and professionals with online access to the existing body of knowledge. Bibliometric studies are a useful method to understand and explore the status and quality of work done by previous researchers through the analysis of publications and citations, which provides a comprehensive overview.

This paper will help researchers and practitioners dealing with supply chain strategies to perceive the scarcity of academic research and publications in the three key areas, namely "supply chain", "optimisation" and "transportation", which are concepts focused on the total supply chain. The results of this bibliometric analysis can also help identify thematic areas, journals and topics to aid the exploration of new opportunities for future research. This study is, however, limited in the way the research method was structured; the results can also be viewed from multiple perspectives.

The inclusion of additional keywords in the search criteria could generate a broader range of articles; however, this would require more sophisticated or innovative bibliometric and network tools. This study utilised VOSviewer and CitNetExplorer software to map the bibliometric statistical results and to generate the most dynamic and understandable overview possible. The illustrated methodology can be used as a guide for developing a reliable supply chain system plan with the lowest possible costs (Daehy et al., 2019).

Finally, the results of the citation analysis show that coordination is a dominant theme, especially in a research community more oriented to the science of administration. Besides, the results of this study indicate that strategic management accounting practices have a significant positive relationship with the supply chain results and that supply chain results have a significant positive relationship with the profitability of logistics companies (Meiwanto and Apollo, 2019). Citation networks show that there are research flows that are 
related to empirical problems of collaboration/cooperation in the supply chain or problems of coordination in the formal and analytical supply chain. Importantly, having the capacity to improve the value for the customer and, at the same time, looking for opportunities to reduce costs, opens new frontiers for managing the supply chain.

\section{References}

Alglawe, A., Schiffauerova, A., Kuzgunkaya, O. and Shiboub, I. (2019), "Supply chain network design based on cost of quality and quality level analysis", TQM Journal, Vol. 31 No. 3, pp. 467-490.

Alsobhi, S.A., Krishnan, K.K., Gupta, D. and Almaktoom, A.T. (2018), "Analysis of damage costs in supply chain systems", International Journal of Industrial and Systems Engineering, Vol. 28, pp. 70-98.

Bastl, M., Grubic, T., Templar, S., Harrison, A. and Fan, I. (2010), "Inter-organisational costing approaches: the inhibiting factors", The International Journal of Logistics Management, Vol. 21 No. 1, pp. 65-88, doi: 10.1108/09574091011042188.

Benrqya, Y. (2019), "Costs and benefits of using cross-docking in the retail supply chain: a case study of an FMCG company", International Journal of Retail and Distribution Management, Vol. 47 No. 4, pp. 412-432.

Carvalho, H., Govindan, K., Azevedo, S.G. and Cruz-Machado, V. (2017), "Modelling green and lean supply chains: an eco-efficiency perspective”, Resources, Conservation and Recycling, Vol. 120, pp. 75-87.

Chen, Lu and Notteboom, T. (2014), "A cost perspective on the location of value-added logistics services in supply chains", International Journal of Logistics Systems and Management, Vol. 18 No. 1, pp. 24-48.

Chen, L., Guiffrida, A.L. and Datta, P. (2018), "Capacity-delivery coordination in supply chains: a cost-based approach", International Journal of Operational Research, Vol. 32 No. 3, pp. 290-312.

Chiadamrong, N. and Wajcharapornjinda, P. (2012), "Developing an economic cost model for quantifying supply chain costs", International Journal of Logistics Systems and Management, Vol. 13 No. 4, pp. 540-571.

Christopher, M. and Holweg, M. (2011), "Supply Chain 2.0": managing supply chains in the era of turbulence", International Journal of Physical Distribution and Logistics Management, Vol. 41 No. 1, pp. 63-82, doi: 10.1108/09600031111101439.

Daehy, Y., Krishnan, K., Alsaadi, A. and Alghamdi, S. (2019), "Effective cost minimisation strategy and an optimisation model of a reliable global supply chain system", Uncertain Supply Chain Management, Vol. 7 No. 3, pp. 381-398.

Datta, P. (2016), "Supply network resilience: a systematic literature review and future research", International Journal of Logistics Management, Vol. 28 No. 4, pp. 1387-1424.

Dos Santos, T.F., Gonçalves, A.T.P. and Leite, M.S.A. (2016), "Logistics cost management: insights on tools and operations", International Journal of Logistics Systems and Management, Vol. 23 No. 2, pp. 171-188.

Ferreira, M.P., Pinto, C.F. and Serra, F.R. (2014), "The transaction costs theory in international business research: a bibliometric study over three decades", Scientometrics, Vol. 98 No. 3, pp. 1899-1922.

González-Benito, J., Lannelongue, G. and Alfaro-Tanco, J.A. (2013), "Study of supply-chain management in the automotive industry: a bibliometric analysis", International Journal of Production Research, Vol. 51 No. 13, pp. 3849-3863.

Hafezalkotob, A. and Khalili-Damghani, K. (2015), "Development of a multi-period model to minimise logistic costs and maximise service level in a three-echelon multi-product supply chain 
BIJ

28,3

1098

considering back orders", International Journal of Applied Decision Sciences, Vol. 8 No. 2, pp. 145-163.

Hames, G., Nilson, M., Rodriguez, C.M.T., da Silva, F.L. and Lezana, A.G.R. (2019), "Reverse logistics costs: case study in a packaging industry", in Reis, J., Pinelas, S. and Melão, N. (Eds), Industrial Engineering and Operations Management I, Springer, Berlin, pp. 33-46.

Havenga, J. (2010), "Logistics costs in South Africa - the case for macroeconomic measurement", South African Journals of Economics, Vol. 78 No. 4, pp. 460-478.

Hofmann, E. and Bosshard, J. (2017), "Supply chain management and activity-based costing: current status and directions for the future", International Journal of Physical Distribution and Logistics Management, Vol. 47 No. 8, pp. 712-735.

Hu, J., Hu, Q. and Xia, Y. (2019), "Who should invest in cost reduction in supply chains?”, International Journal of Production Economics, Vol. 207 No. 1, pp. 1-18.

Ilin, I.V. and Anisiforov, A.B. (2014), "Improving the efficiency of projects of industrial cluster innovative development based on enterprise architecture model", WSEAS Transactions on Business and Economics, Vol. 11, pp. 757-764.

Jeffery, M.M., Butler, R.J. and Malone, L.C. (2008), "Determining a cost-effective customer service level”, International Journal of Supply Chain Management, Vol. 13 No. 3, pp. 225-232.

Jena, N. and Seth, N. (2016), "Factors influencing logistics cost and service quality: a survey within the Indian steel sector", Industrial and Commercial Training, Vol. 48 No. 4, pp. 199-207.

Liu, Z. and Nagurney, A. (2013), "Supply chain networks with global outsourcing and quick-response production under demand and cost uncertainty", Annals of Operations Research, Vol. 9 No. 208, pp. 251-289.

Lukinskiy, V., Valeryevich, L. and Zamaletdinova, D. (2015), "Integrated method of analysing logistics costs in supply chain", International Journal of Supply Chain and Inventory Management, Vol. 1, pp. $48-61$.

Mangal, D. and Gupta, T.K. (2015), "Management of demand uncertainty in supply chain cost planning", International Journal of Logistics Systems and Management, Vol. 22, pp. 399-413.

Mangla, S.K., Luthra, S., Jakhar, S.K., Tyagi, M. and Narkhede, B.E. (2017), "Benchmarking the logistics management implementation using Delphi and fuzzy DEMATEL”, Benchmarking: An International Journal, Vol. 25 No. 6, pp. 1795-1828.

Manzouri, M., Ab-rahman, M.N., Rosmawati, C., Mohd, C. and Jamsari, E.A. (2014), "Increasing production and eliminating waste through lean tools and techniques for halal food companies", Sustainability, Vol. 6 No. 12, pp. 9179-9204.

Masoud, S.A. and Mason, S.J. (2015), "Integrated cost optimisation in a two-stage automotive supply chain", Computers and Operation Research, Vol. 67 No. 3, pp. 1-11.

Meiwanto, C. and Apollo (2019), "The contribution of strategic management accounting in supply chain outcomes and logistic firm profitability”, Uncertain Supply Chain Management, Vol. 7, pp. 145-156.

Merigó, J.M. and Yang, J. (2017), "A bibliometric analysis of operations research and management science”, Omega, Vol. 73 No. 12, pp. 37-48.

Ozkoze, H. and Gencer, C. (2017), "Bibliometric analysis and mapping of management information systems field”, Journal of Science, Vol. 30 No. 4, pp. 356-371.

Pettersson, A.I. and Segerstedt, A. (2013), "Measuring supply chain cost", International Journal Production Economics, Vol. 143 No. 2, pp. 357-363.

Prajogo, D., Oke, A. and Olhager, J. (2016), "Supply chain processes: linking supply logistics integration, supply performance, lean processes and competitive performance", International Journal of Operations and Production Management, Vol. 36 No. 2, pp. 220-238.

Rybakov, D.S. (2017), "Total cost optimisation model for logistics systems of trading companies", International Journal of Logistics Systems and Management, Vol. 27 No. 3, pp. 318-342. 
Saha, V., Mani, V. and Goyal, P. (2020), "Emerging trends in the literature of value co-creation: a bibliometric analysis", Benchmarking: An International Journal, Vol. 27 No. 3, pp. 981-1002.

Seuring, S. and Muller, M. (2008), "From a literature review to a conceptual framework for sustainable supply chain management", Journal of Cleaner Production, Vol. 16 No. 15, pp. 1699-1710.

Shiau, W. and Dwivedi, Y.K. (2013), "Citation and co-citation analysis to identify core and emerging knowledge in electronic commerce research", Scientometrics, Vol. 94 No. 5, pp. 1317-1337.

Silva, T.F., Gonçalves, A.T. and Leite, M.S. (2014), "Logistics cost management: insights on tools and operations", International Journal of Logistics Systems and Management, Vol. 19 No. 3, pp. 329-346.

Singh, G. and Pandey, N. (2019), "Revisiting green packaging from a cost perspective: the remanufacturing vs new manufacturing process", Benchmarking: An International Journal, Vol. 26 No. 3, pp. 1080-1104.

Solakivi, T., Hofmann, E., Töyli, J. and Ojala, L. (2018), "The performance of logistics service providers and the logistics costs of shippers: a comparative study of Finland and Switzerland", International Journal of Logistics Research and Applications, Vol. 21 No. 4, pp. 1-20.

Somapa, S., Cools, M. and Dullaert, W. (2012), "Unlocking the potential of time-driven activity-based costing for small logistics companies", International Journal of Logistics Research and Applications, Vol. 15 No. 5, pp. 303-322.

Van Eck, N.J. and Waltman, L. (2010), "Software survey: VOSviewer, a computer program for bibliometric mapping”, Scientometrics, Vol. 84 No. 2, pp. 523-538.

Van Eck, N.J. and Waltman, L. (2017), "Citation-based clustering of publications using CitNetExplorer and VOSviewer", Scientometrics, Vol. 111 No. 2, pp. 1053-1070.

Vishnu, C.R., Sridharan, R. and Kumar, P.N.R. (2019), "Supply chain risk management: models and methods", International Journal of Management and Decision Making, Vol. 18 No. 1, pp. 31-75.

Voordijk, H. (2010), "Physical distribution costs in construction supply chains: a systems approach", International Journal of Logistics Systems and Management, Vol. 7 No. 4, pp. $456-471$.

Wang, J.J., Chen, H., Rogers, D., Ellram, L.M. and Grawe, S.J. (2017), “A bibliometric analysis of reverse logistics research", International Journal of Physical Distribution and Logistics Management, Vol. 47 No. 8, pp. 666-687.

Weiyi, F. and Luming, Y. (2009), "The discussion of target cost method in logistics cost management", ISECS International Colloquium on Computing, Communication, Control, and Management, Vol. 4 No. 1, pp. 537-540.

Weskamp, C., Koberstein, A., Schwartz, F., Suhl, L. and Voß, S. (2018), "A two-stage stochastic programming approach for identifying optimal postponement strategies in supply chains with uncertain demand", Omega, Vol. 83, pp. 123-138.

Whicker, L., Bernon, M., Templar, S. and Mena, C. (2009), "Understanding the relationships between time and cost to improve supply chain performance", International Journal of Production Economics, Vol. 121 No. 2, pp. 641-650.

Xiao, D., Wang, J. and Lu, Q. (2020), "Stimulating sustainability investment level of suppliers with strategic commitment to price and cost sharing in supply chain", Journal of Cleaner Production, Vol. 252 No. 4, pp. 1-34.

Ying, F., Tookey, J. and Seadon, J. (2018), "Measuring the invisible: a key performance indicator for managing construction logistics performance", Benchmarking: An International Journal, Vol. 25 No. 6, pp. 1921-1934. 
BIJ

28,3

1100

Zhang, C., Coronado, A. and Feng, Y. (2013), "Methodological review of logistics and supply chain management research in China”, International Journal of Applied Management Science, Vol. 5 No. 3, pp. 200-216.

\section{Further reading}

Bastas, A. and Liyanage, K. (2019), "Integrated quality and supply chain management business diagnostics for organisational sustainability improvement", Sustainable Production and Consumption, Vol. 17 No. 1, pp. 11-30.

Cousins, P.D., Lawson, B. and Squire, B. (2006), "Supply chain management: theory and practice - the emergence of an academic discipline?", International Journal of Operations and Production Management, Vol. 26 No. 7, pp. 697-702.

\section{Corresponding author}

Ben Hazen can be contacted at: hazenscm@gmail.com

For instructions on how to order reprints of this article, please visit our website: www.emeraldgrouppublishing.com/licensing/reprints.htm Or contact us for further details: permissions@emeraldinsight.com 